Historic, archived document

Do not assume content reflects current scientific knowledge, policies, or practices. 

Suggested Layouts For
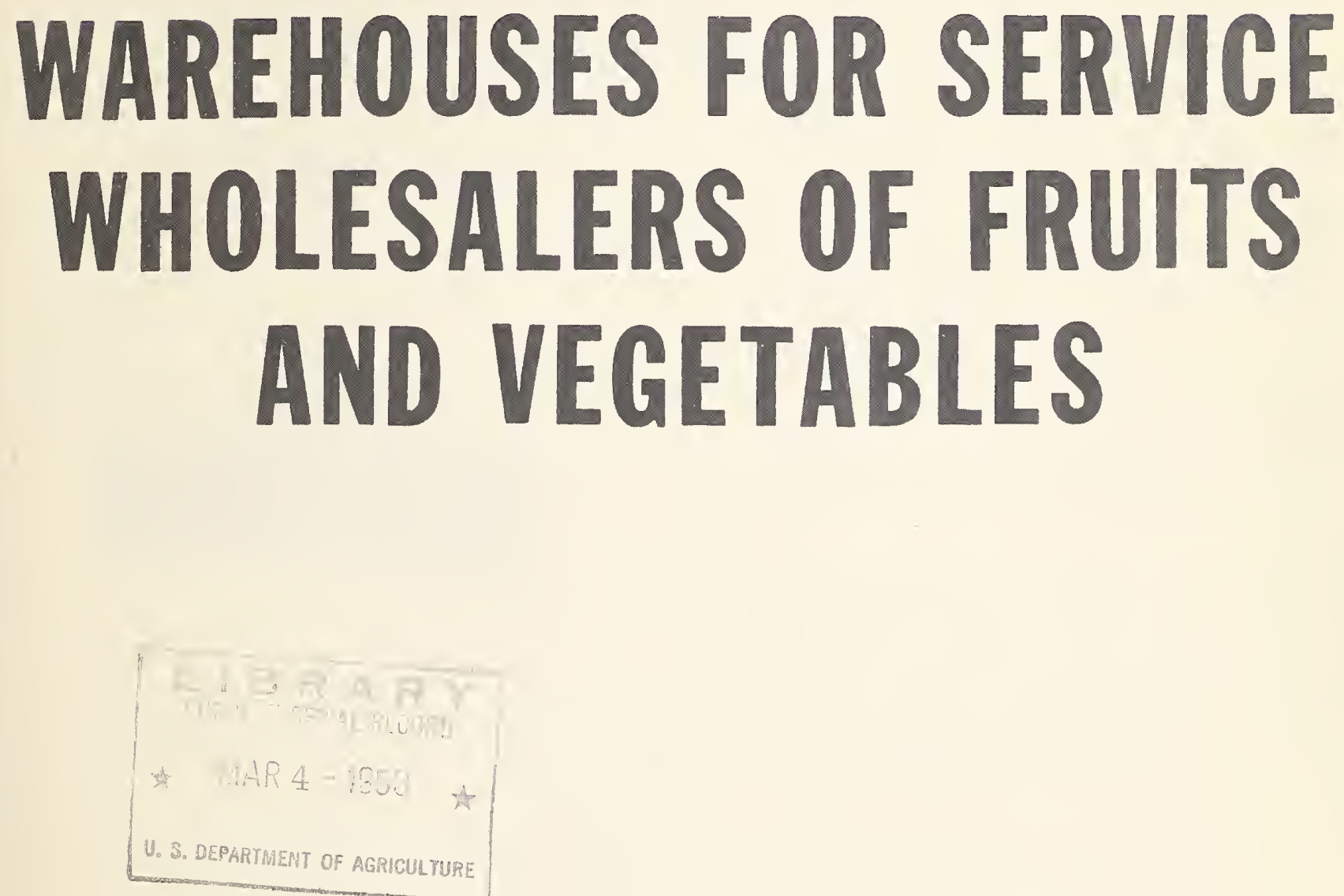

AMS 228

UNITED STATES DEPARTMENT OF AGRICULTURE

Agricultural Marketing Service Marketing Research Division 
- 


\section{SUGGESTED LAYOUTS FOR WAREHOUSES FOR SERVICE WHOLESALERS OF FRUITS AND VEGETABLES}

By Robert K. Bogardus, industrial engineer, Transportation and Facilities Branch, Marketing Research Division

As used in this report, the term "service wholesaler" means a wholesale distributor who obtains orders for fruits and vegetables through salesmen or by telephone and who makes deliveries to his customers. Many of these wholesalers are interested in adopting improved methods of handing fruits and vegetaoles but are finding that these methods cannot be efficiently used in their old facilities, some of which are antiquated. As a consequence, a number of wholesalers are planning either to construct new facilities or to remodel existing buildings.

The Agricultural Marketing Service has initiated engineering research to develop detailed plans and specifications for warehouses for different scales of operation in different regions. The studies will provide service wholesalers with guides and standards for the layout and structural design of warehouses. Initial work covers the design of a warehouse for a dealer handling 1,000 carlots per year in the latitude of Cincinnati, Ohio. The design for this warehouse will be modified to adapt it to weather conditions-including wind, snow loads, temperatures and humidities--in the New Orleans, La., and Minneapolis-St. Paul, Minn., areas.

The purpose of this preliminary report is to present the suggested layouts for service wholesale warehouses that have been completed as a first step in the engineering research. Each of the layouts provides for an efficient warehousing operation. A comprehensive report will be prepared on completion of the research. Complete details on the warehouse layout development, structural design, building materials, specifications, costs of construction, and modifications for locations other than Cincinnati will be included in the later report.

As a first step in designing the 1,000-car warehouse, 2 layouts were prepared. $\underline{1} /$

1/ These layouts were developed by the McPherson Company, Architects and Engineers, Greenville, S. C., under a research contract with the U. S. Department of Agriculture. This contract also covers the design work. 
A suggested layout for a warehouse approximately square in shape is shown in figure 1. A second suggested layout for a warehouse, with no limitations on the relationship of width and depth, is shown in figure 2. 2/

\section{LAYOUT REQUIREMENTS}

\section{Characteristics of the Service Wholesale Business}

The following assumed characteristics of a service wholesale enterprise were used to determine the amount of floor space required as shown in both layouts:

1. Of the 1,000 carload equivalents handled annually, rail receipts account for 450 carloads, and motortruck receipts account for 550 carloads.

2. Eighty percent of the total annual volume is handled in an 8-month period from early fall to late spring; the remaining 20 percent is handled during the 4 summer months. During the 8-month period, the average weekly receipts by rail are 10 carloads and by motortruck 13 carloads.

3. The maximum volume shipped out on any 1 day is 6 carloads. This quantity is loaded out on 16 delivery trucks having an average load per truck of approximately 6 tons.

4. A maximum volume of 1 carload equivalent of bananas is to be cut and packed daily.

\section{Storage Requirements}

The total annual volume of fruits and vegetables handled was broken down into 4 categories on the basis of differences in temperature and humidity required to provide optimum storage conditions. Whenever package strengths permitted, all loaded pallets were to be stored 2 high.

On the basis of this breakdown, a general storage area, to be held at a temperature of $50^{\circ} \mathrm{F}$., would be required to store 7 carload equivalents of cantaloupes, onions, potatoes, sweetpotatoes, tomatoes, and related items. A dry cold-storage room, in which the temperature would be $32^{\circ} \mathrm{F}$. and the humidity would vary between 85 and 90 percent, would be required for storing 5 carload equivalents of apples, grapefruit, grapes, lemons, lettuce, oranges,

2/ Detailed plans and specifications for a warehouse incorporating the layout shown in figure 2 will be developed under the research contract referred to in footnote 1 . 


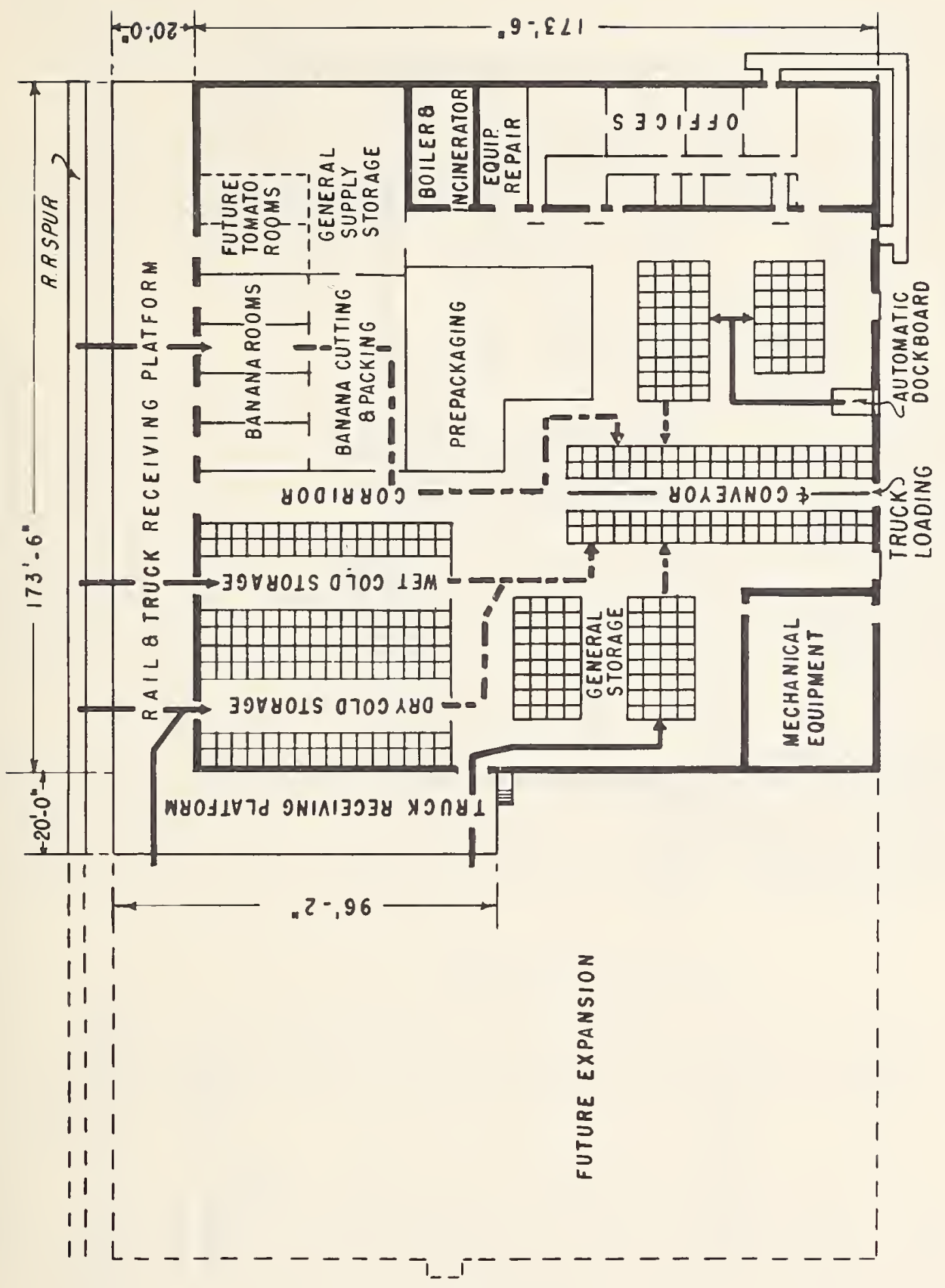




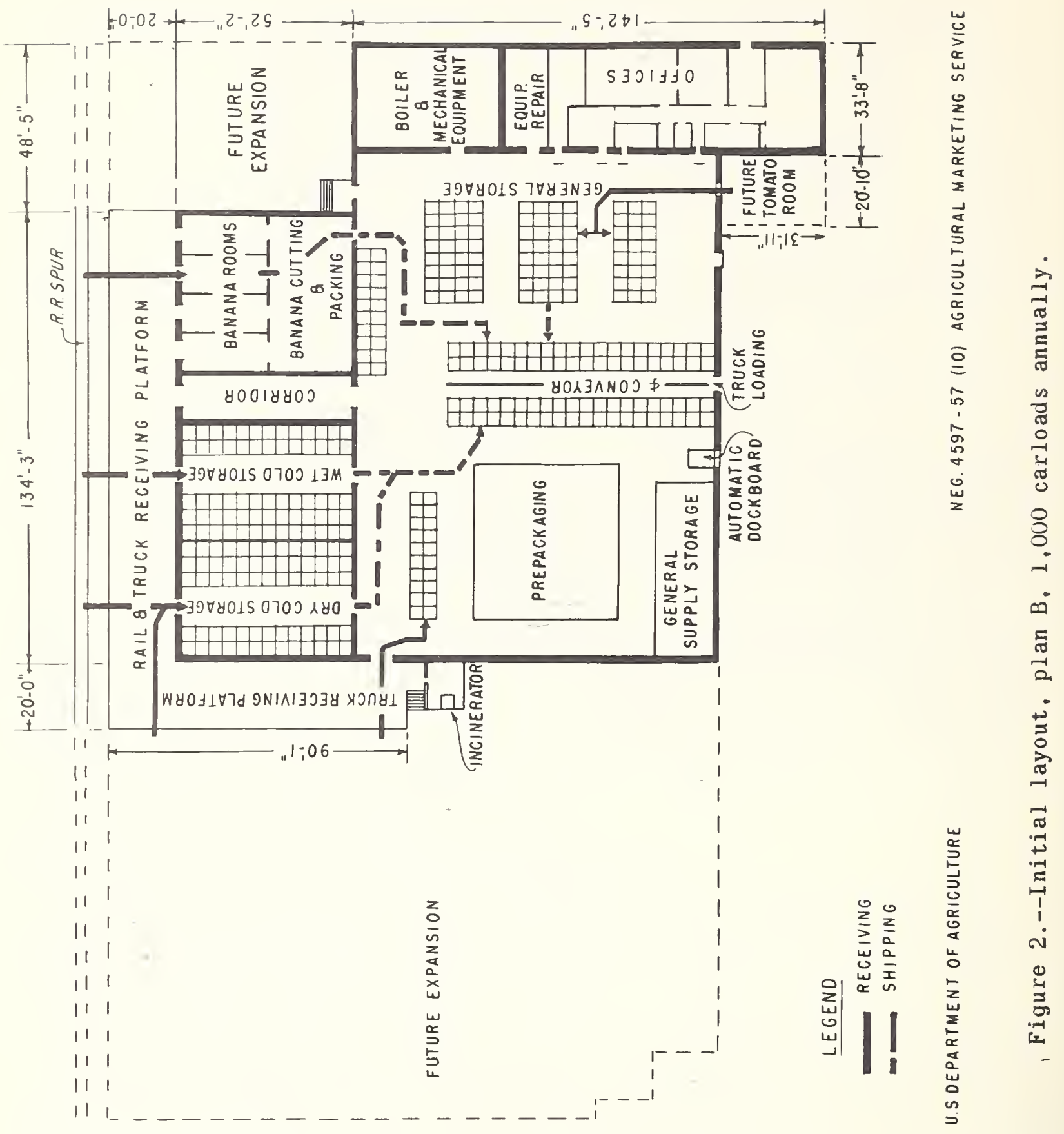


peaches and related items. A wet cold-storage room also would be required, with the humidity between 90 and 95 percent and the temperature at $32^{\circ} \mathrm{F}$, for storing 3 carload equivalents. Items stored under these conditions include cabiage, carrots, celery, corn, and similar produce.

Four rooms for ripaning and holding bananas, at temperature ranges of 56 to $70^{\circ} \mathrm{F}$. and humidity ranges of 85 to 95 percent would be needed. Four carload equivalents of bananas would be stored in these rooms. The temperatures maintained in the banana cutting and packing room would range froin 56 to $60^{\circ} \mathrm{F}$.

\section{Materials-Handling Methods}

In developing these layouts, it was assuned that commodities, other than bananas, received by both railroad and motortruck, would be built into unit loads on 40 - by 48 -inch wood pallets on the receiving platforms. These loads then would be picked up by electric pallet transporters or forklift trucks, and transported to and placed in storage. These methods require an industrial forklift truck with capasity to handle a 2,000-pound load ani to elevate it high enough to place l pallet load on top of another. The same equipment would be used to move the unit loads out of the storage areas to a position immediately adjacent to a belt conveyor.

A portable belt conveyor with a retractable cantilevered extension would be used to move the commodities into delivery trucks. Four-wheel hand platform trucks, having superstructures for hanging stems of fruit, would be used for receiving bananas. The stems of green fruit would be hung manually from ceiling hooks in the ripening rooms. The stems of ripe bananas would be transported to the cutting and packing areas on the same equipment.

\section{WAREHOUSE FEATURES}

The warehouse would be of steel frame construction with exterior walls of concrete masonry with a brick facing. Floors would be reinforced concrete on compacted earth fill. The roof and exterior and interior walls would be insulated.

Door openings for fork-truck operations would be at least 6 feet wide and $7 \frac{1}{2}$ feet high. The warehouse floor would be 55 inches above the top of the rails on the railroad receiving side, 48 inches above the road surface on the truck receiving side, and 45 inches above the road surface on the truck loading side. Net clear ceiling height above the floor would be 12 feet. 


\section{LAYOUT CONSIDERATIONS}

In developing the layouts discussed in this report, several factors were considered as a basis for an efficient warehousing operation. Space requirements were based on the volumes of fruits and vegetables to be handled and the types of materials-handling equipment to be used. The tonnages of each commodity to be stored determined the number of loaded pallets for which storage space was required. The pallet size ( 40 by 48 inches) plus clearances for ease in movement and positive air circulation established the storage areas needed. In addition, aisle widths were made great enough to provide quick, easy access to all commodities.

The various warehouse components were arranged in such a way that commodities could be moved over short, direct paths to their storage places. Conveyors for truck loading were centrally located so that movement from storage to the conveyor line would be short and direct. Enough space was provided along the conveyors to permit the temporary storage of complete pallet loads of commodities required to satisfy customer orders.

Pallets loaded on the receiving platform would not be unloaded until they were placed in the conveyor area for delivery-truck loading. Warehouse doors. aisles, and storage areas were arranged so that these materials-handling systems could be used in the most efficient manner. Adequate provision was made also for supplementary handling systems for bananas and for other warehouse operations.

Large, open areas were provided for general storage, to permit easy, rapid adjustment for different pallet storage patterns and modified handling systems.

Provision for expansion was made, since all new warehouses should be constructed so as to permit their orderly expansion. The layouts shown in figures 1 and 2 were developed so as to permit the expansion of the buildings to handle efficiently 2,000 carload equivalents, or double the initial volume. Figure 3 shows the suggested layout of the square building (fig. 1) after its expansion for handling 2,000 carload equivalents, including the handing and ripening of tomatoes. Figure 4 shows the suggested layout, after expansion, of the building shown in figure 2 .

\section{ARRANGEMENT AND FUNCTIONAL USE OF WAREHOUSE COMPONENTS}

Receipts palletized on the railroad or truck platforms would move over short, direct paths to their designated storage areas. During the assembly operation, unit loads on pallets would be withdrawn from their respective storage areas. Palletized loads of packed boxes of bananas would be picked up from the banana-cutting room or from a holding room. All loads would move directly to the order assembly area. The paths of commodity movement into, through, and out of the warehouse are indicated by flow lines. 


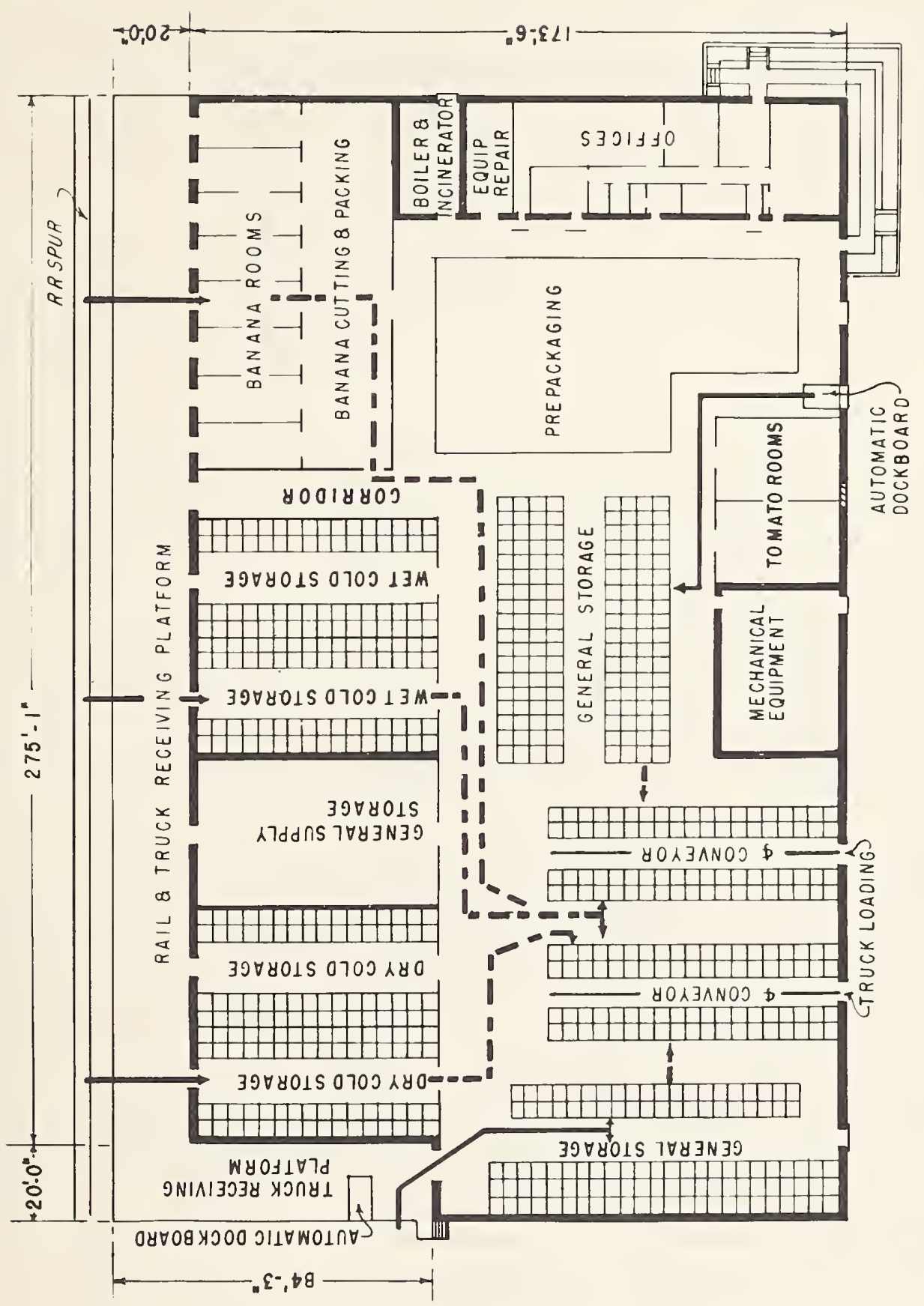

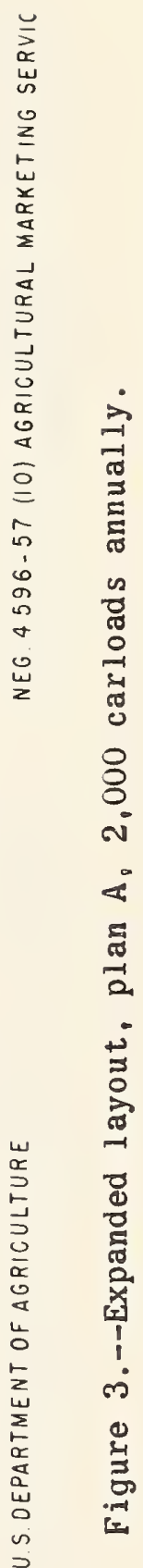




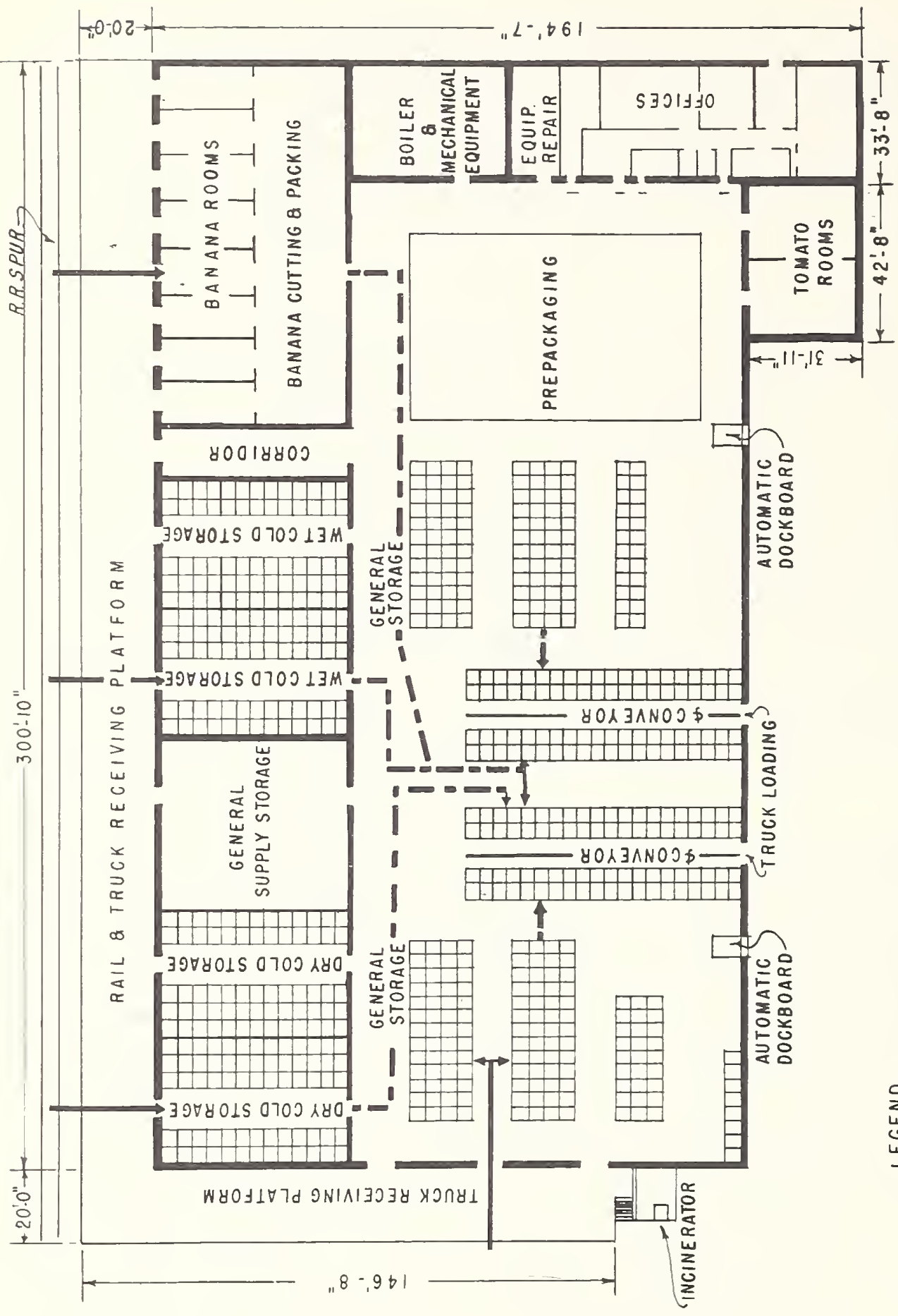

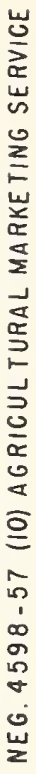

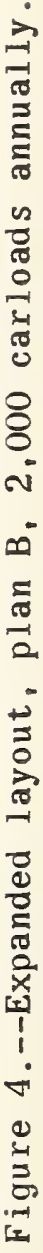


The small. squares on each layout represent the space required for 1 pallet or 2 pallets tiered. Whenever package strength permits, all loaded pallets would be stored 2 high to minimize the floor areas required. In the cold-storage rooms, pallets would be stowed in 2 rows, 2 or 3 pallets deep in each row. Aisles would be a mininum of 11 feet wide to permit easy movement of pallets into and out of storage position. Wider aisles would be provided whenever fairly regular two-way traffic would take place.

Each banana room would have a carload capacity. Cutting and packing space would be adequate for equipment needed to pack as much as a carload of ripe bananas in 1 day. A general supply area was included to permit storage of empty boxes and pallets, paper, packaging materials, office supplies, and related equipment.

Space was provided in the general storage section of the warehouse for prepackaging and reconditioning fruits and vegetables. There would be sufficient space for the installation of the equipment needed for a small prepackaging operation. If tomatoes were ripened in this warehouse, the sorting and packing tables as well as the overwrap machinery would be located in this area.

A mechanical equipment room was included to house the refrigeration equipment. Enough area was made available in the initial layouts to permit tile installation of the units required when the warehouse would be expanded. The space indicated for equipment repair would provide room for facilities for charging the batteries used in the handling equipment and for maintenance and repair of that equipment.

The remaining space represents the railroad and motortruck platforms. A canopy would cover each platform and extend beyond the edge of each truck platform. The platforms would be 20 feet wide, to provide room for building loads on pallets and for easy, unhampered movement of the forklift trucks and pallet transporters. Certain sections of the platform could be used for storage of empty pallets.

Door openings were provided in sufficient numbers for quick access to any warehouse storage area. In at least one door opening, an automatic dockboard would be installed. Commodities could be received here and small shipments, occurring at irregular times, could be made. 
- 